\title{
IMPACT OF STUDENTS' RESEARCH PROJECTS INTO LEARNING ENHANCEMENT FOR CORE CURRICULUM CLASSES IN CS/IT
}

\author{
Ardian N. Greca, Georgia Southern University, agreca@georgiasouthern.edu \\ E. Sonny Butler, Georgia Southern University, esbutler@georgiasouthern.edu
}

\begin{abstract}
The goal of this research is to analyze the impact of students' research projects into rapid feedback and learning for the core curriculum classes in the Computer Science and Information Technology programs. There is a need emerging, because of the rapidly advancing technological innovations, for university instructors to innovate new methodology for delivering instructional pedagogy. This paper will present a detailed analysis of the methodology used along with an assessment of the final method. This method has been implemented in logic circuit design, data communications, and networking courses, as well as in some of the introductory programming courses. We also will discuss our evaluation criteria and present the results achieved in the last three years. Student learning has improved, their interest in the topics has increased and the methodology can be implemented easily in different core curriculum classes for the Computer Sciences and Information Technology programs.
\end{abstract}

Keywords: Student Research Projects, Interactive Teaching Pedagogy, Computer Science, Information Technology Curriculum, Technological Innovation

\section{INTRODUCTION}

Research suggests that with rote learning, students can only maintain the information gained six to eight weeks [8]. But learning is enhanced where learners have supportive relationships, have a sense of ownership and control over the learning process, and can learn with and from each other in a safe and trusting learning environment. Most of the current teaching methodologies are designed to promote knowledge/information transfer. Instructors will prepare the lessons and explain (transfer) the concepts to students in the classroom [10]. While knowledge transfer is a necessary component of learning, it is not sufficient by itself to change learning behavior. Students need to improve their skills and develop proficiency in performing a particular task by actively participating in labs (especially hands-on labs). However, students still have not learned how to adapt and apply the skills learned in different contexts. To complete the learning process and deliver the technological skills that companies want, students need to develop these skills with a hands-on research project which will put them in a real-world environment [4].

There are many factors that make teaching core curriculum classes for a Computer Science/Information Technology program difficult. Some of these factors are

- understanding the binary number concept and their logic for the first time,

- understanding logic design for the first time,

- experiencing new technology and environment,

- experiencing a new work ethic,

- differing student backgrounds and abilities.

Teaching these courses presents many challenges to instructors. There is an immediate need for instructors to introduce innovative instructional pedagogy in order to increase feedback and increase retention times $[1,2,3,7]$.

By dealing with the many problems and difficulties discussed in the literature, our challenge is how to improve and enhance learning outcomes for students who complete core courses in CS and IT programs at Georgia Southern University. To assist in accomplishing this, besides using the traditional teaching methodology of tests, quizzes, labs, prepared lessons and home work, we have designed a student research project. This research project is the only project of its type to be integrated into the CS/IT curricula. It requires students to work in teams and prepare a report on a topic related to the material covered in class. After $2 / 3$ of the material is covered in class, students have one week to choose a topic related to the concepts discussed in respective courses. They are required to pick a topic of interest related to the course and perform research, using the library, the Internet and other available resources. The research project is unique and different from other group projects which mostly are prepared by the instructors and given to the students. In this research project students are required to select their topic and prepare their objectives in an independent environment. They will put themselves in a realworld environment and use the knowledge gained 
during the course in a productive manner. Students will complement the learning process of the course and will have the opportunity to test and deliver their technical skills learned. The results obtained so far using this method confirm that students' learning is improved, their interest in the topic is increased and the method can be implemented easily in different core curriculum classes.

\section{DEVELOPMENT OF THE CONCEPT}

Before introducing our approach, let us explain how to prepare the background for applying the methodology. We offer a "logic circuits and microprocessors design" course three days a week. There are two academic hours for lectures and two for laboratories. The "data communication and networking" course is offered two days a week with four academic hours for lectures. Also we offer an "introduction to programming" course three days a week with two academic hours for lectures and two for laboratories. During the lectures the concepts and examples are explained to students and they are then required to answer some questions regarding the topics covered. There are approximately five quizzes, two projects and several homework assignments. During the semester each problem is carefully designed to measure progress and continuity between the problem and the topics discussed. A list of expected outcomes on each of these classes was decided at the departmental level and have been consistently used as part of the course syllabi for several years and used by all sections. The selection of the appropriate book $[5,6,9,12]$ for the course is decided at the department level.

We want our research project to be part of the learning process and base its success on two very important issues: constructive learning and pair working [11].

\section{Constructive Learning}

Backed by theoretical framework, the central notion of constructive learning is that understanding and learning need to be active, constructive, generative processes such as assimilation, augmentation, and self reorganization. This means that an instructor's words do not simply become directly engraved in a student's mind, but those words are influenced and interpreted by the student. Since the research project requires students to interpret their work, they are led to the constructive learning concept. They are participants in the learning process-not just spectators.

\section{Pair Working}

The central idea of pair working is that learning is the process in which learners become collaborative by common practices, language, use of tools, values, beliefs, and so on. The goal is to enable practices that are appropriate in the professional culture of the domain under study. Pair working has been discussed for a long time. For example, XP (extreme programming) uses pair programming to generate more code and higher quality code than the same two programmers working separately. Programming pairs help to correct each other. They discuss design and coding issues and this helps them to better understand what they are trying to do and to sustain necessary and sometimes prolonged efforts in order to produce working programs. Pair programming is especially helpful when students have diverse backgrounds. In our project, work pair working is not limited to two students, but is open to a group of students. Furthermore, students are required to choose their partners and there is no assignment of group members by the instructors. Thus, students with the same topic of interest will work together to complete the project and increase its quality.

We ask students to choose the topics and work using the guidelines set by the instructors. The topic might be a simple design such as the circuit for a keyless entry system, circuits for arithmetic operations, or more complicated circuits such as simulation of a circuit for elevators, alarm clocks, DSL technologies, wireless connections etc. During the second week, students are asked to prepare a one-page abstract of their project. Then in the following week they prepare a paper of about 10 pages in length. Finally, they have to present their work during the next class meeting. The guidelines for writing the paper are given to students in advance and are shown below:

- Introduction Section: General background about the paper topic, as well as the structure of it are explained here.

- Technical Section: The techniques used in the selected topic are presented in this section.

- Summary Section: This section is used to summarize the topic chosen. It also includes some conclusions or observations done by students.

- Reference Section: This section includes a full list of all sources used.

Students are required to follow these guidelines; however, they may introduce new sections depending on the topic of their presentation. 


\section{RESULTS AND DISCUSSIONS}

Student research projects integrate authentic realworld scenarios into the classroom. Some of the basic ideas in this process are to give students the responsibility for defining their learning objectives and experience the planning necessary to solve problem(s) and to encourage collaborative learning among teams. This learning method better reinforces learned concepts. Since students come up with their own original ideas on designing the project and use the knowledge obtained during the course, the material presented in the course becomes more coherent and this contributes to the students having a well-constructed body of knowledge.

Figure 1 shows the collaboration between three components of learning. Each one reinforces the other two and learning is most efficient when all three components are accomplished.

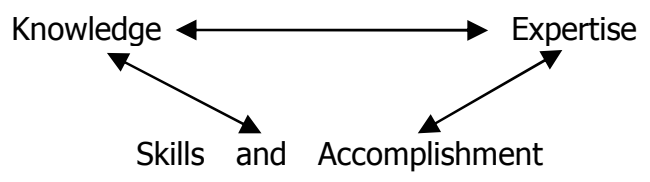

Figure 1. Collaboration Between Three Components of Learning

Measuring outcomes of the learning process is an important issue to close the loop of this concept. Instructors have considered the following questions important for evaluating success:

\section{Q1: What changes in the teaching process can be} observed that enhance learning?

Teaching logic design courses in the CS curriculum poses some special challenges. The main one is that students are faced for the first time with difficult concepts and they will "get by" without working with and experiencing real world applications. The course must be designed and organized to provide these opportunities.

Research shows that grade point average is one of the best indicators of success in a course [11]. Table 1 summarizes the GPA class average for "logic circuits and microprocessors design" courses offered since Fall 2002. As shown in this table, the student GPA has increased from Fall 2002 to Spring 2005.
Table 1. Ave Students' GPA for Different Terms

\begin{tabular}{ccccc} 
Term & $\begin{array}{c}\text { Fall } \\
\mathbf{2 0 0 2}\end{array}$ & $\begin{array}{c}\text { Fall } \\
\mathbf{2 0 0 3}\end{array}$ & $\begin{array}{c}\text { Fall } \\
\mathbf{2 0 0 4}\end{array}$ & $\begin{array}{c}\text { Spring } \\
\mathbf{2 0 0 5}\end{array}$ \\
\hline \# Students & 18 & 18 & 15 & 15 \\
Ave. GPA & 2.67 & 2.9 & 3.2 & 3.2
\end{tabular}

Besides the above results, we observed that final exam scores of students have improved. There is an increase in the number of students scoring more than 70 points, a moderate increase in students scoring more than 80 points and a smaller increase in students scoring 90 points or higher, on a scale of 0 to 100 . The same trend is observed in other courses where the research projects were introduced but are not shown in this paper.

Q2: How do students use the knowledge and complex reasoning when compared to the recall of low-level information?

We consider two aspects. One is the interaction between students and their instructor, and the other is the breadth and depth provided by requiring realworld applications to be researched and presented by students. In order to succeed and attain the first objective, instructors must take a genuine interest in and be involved with their students. This interest starts with discussions and other interactions with students. Providing extra office hours for students allows them to meet with their instructor and present their progress and express their interests in a less threatening environment. Furthermore, to better measure improvement, the change in average GPA should also be accompanied with an average degree of difficulty assigned to the projects. In the Fall 2002 semester there were many papers covering microprocessors and their history. These papers had a lack of breadth since they involved mostly the evolution of microprocessors and they did not discuss technical specifications. In the Fall 2003 semester there was a broader coverage of important topics, including those on arithmetic circuits. These circuits were designed and simulated by students. In the Fall 2004 semester there were even more interesting topics including those on "Printable Circuits," "Gallium Arsenide Chips," "Nanotechnology," etc. There were also presentations on student designed circuits such as "Home Entry Keypad," "Alarm Clock," "Assembly Programming," etc. Students designed and simulated these circuits using Altera's software tools. In the Spring 2005 semester topics included "Cell Microprocessors," "Xbox Mod Chips," "Arithmetic Operation Circuits," etc. Again most of the designs were simulated in the classroom. 

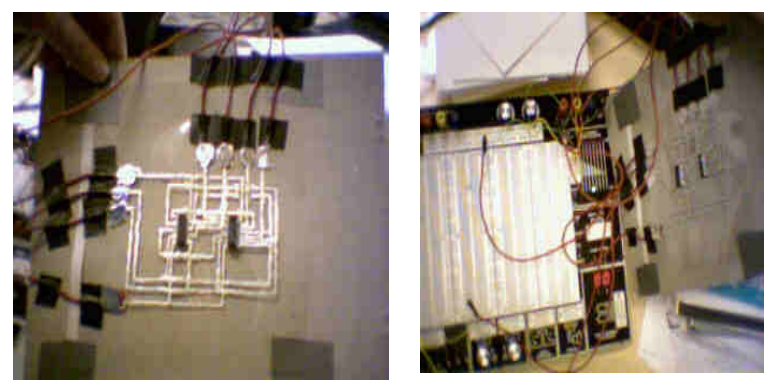

Figure 3. Printable Circuits

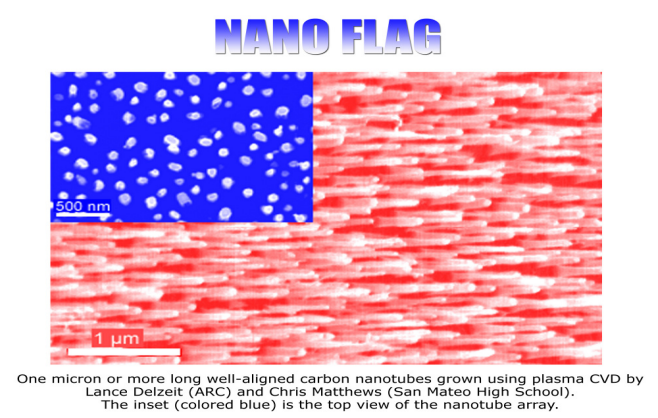

Figure 4. Project on Nanotechnology

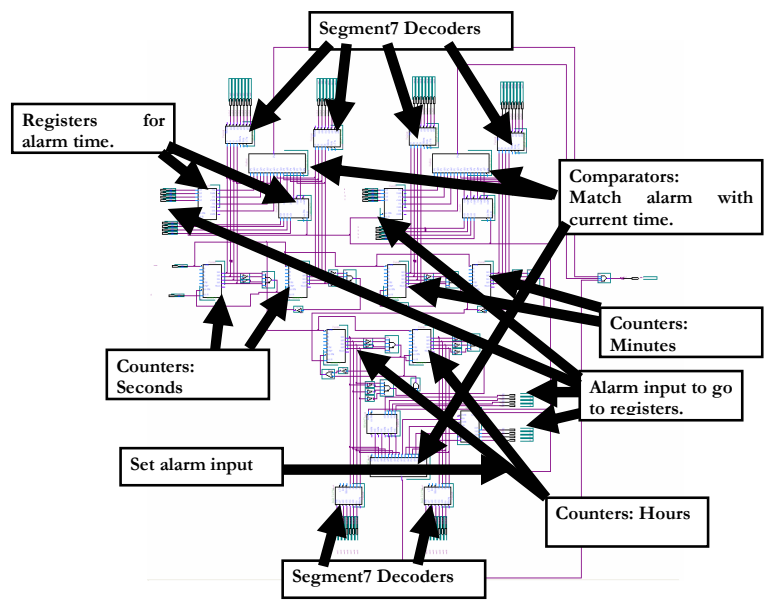

Figure 5a. Project on Alarm Clock Circuits

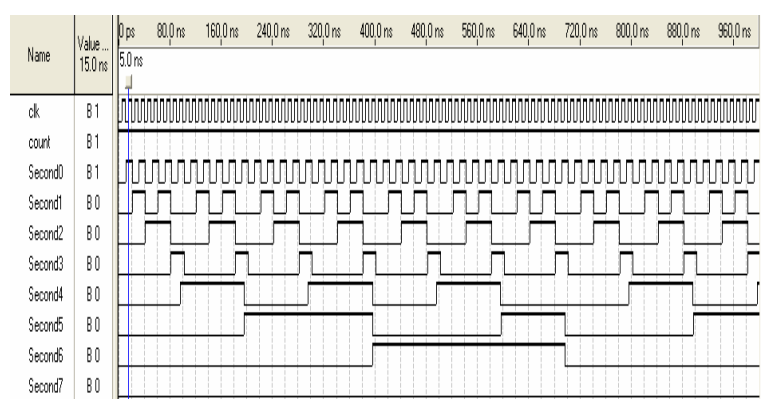

Figure 5b. Project on Alarm Clock Circuits
Figures 3, 4 and 5 show some selected projects on logic circuits and microprocessors design course. Project on "printable circuits" and "alarm clock circuits" were totally designed by students, while the project on "nanotechnology" was a presentation using available knowledge from literature.

Figure 6 shows a project for the Introduction to Programming course. In this project students designed the "blackjack" game. The coding was a novel one and used a lot of the knowledge obtained from the lecture in the class. Note that students involved in this project were freshmen students.

Figures 7, 8 and 9 show selected students' projects from the data communication course, network security, satellite communication and Internet telephony. Note that the student who completed the Internet Telephone project made a demonstration in the classroom calling his classmate's cell phone from his computer connected to the campus network.

Student interest and the range of topics have increased over time. The results gathered so far are promising and students have demonstrated they have a better understanding of core concepts.

\section{CONCLUSIONS}

In this paper we have analyzed the impact of students' research projects into rapid feedback and learning for core curriculum classes in the Computer Sciences and Information Technology programs. So far, results have shown that our goals are being met and confirmed the following:

- the method can produce effective learning,

- it can contribute to rapid feedback,

- students' interest in the topics is increased,

- the grading would be based on students' achievements, and

- students are proud of their work and it is "fun" for students to present their work.

Another important conclusion for this method is that it can be productive only if all components of learning are implemented correctly and continuously. Students seem to be receptive to this method, and as shown, it can produce effective learning. Additional research using this method for other courses would be interesting and may assist us as educators to share our subject knowledge. Other courses that may be appropriate for this method are computer architecture and some elective courses required for the appropriate major. So far, over 200 students have completed the courses under discussion in this paper. Experimental results obtained so far have improved both our methodology and student results. 


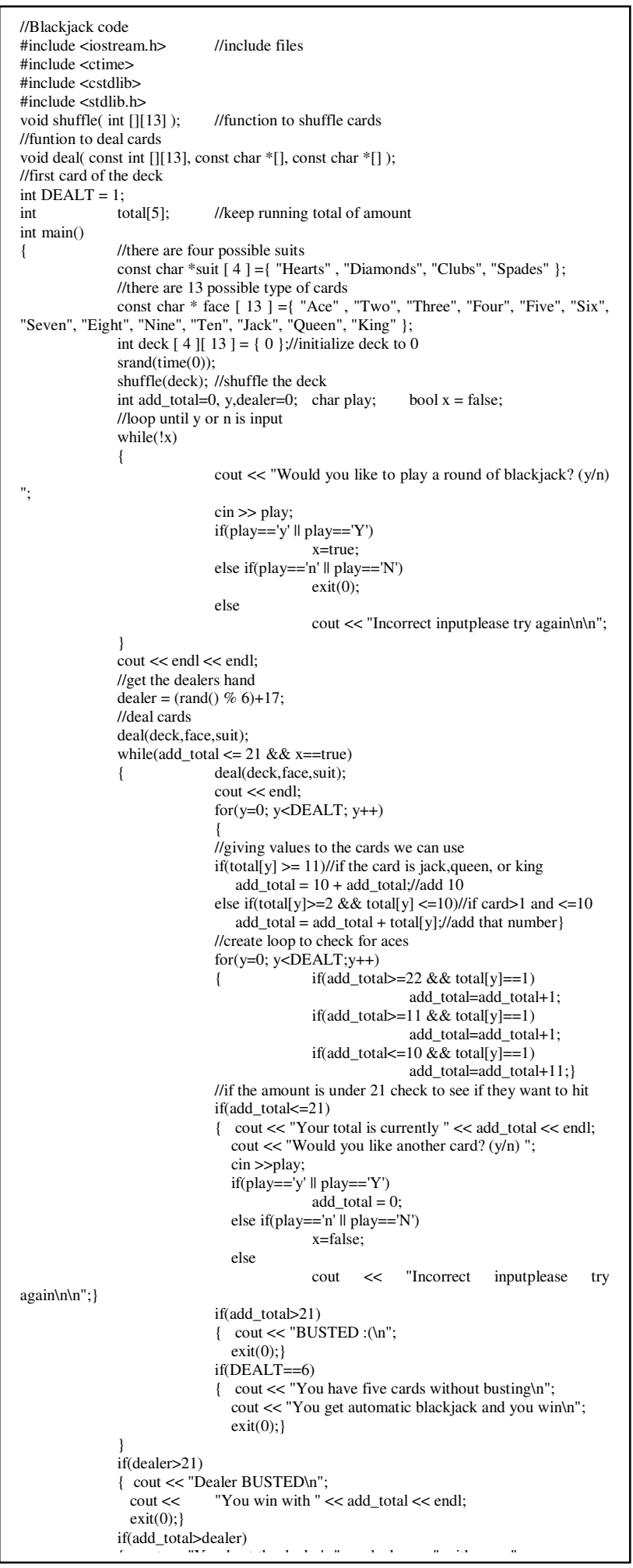

Figure 6. Project in Introduction to Programming Course

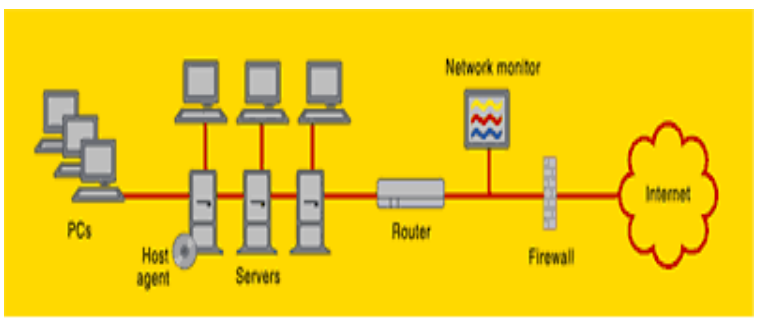

Electronic Eyes. An Intrusion Detection System (IDS) monitors network traffic or file activity on a host for attacks, anomalous behavior, and misuse. An IDS logs intrusions, send real-time alerts, and in some situations can halt the attad.

Figure 7. Project on Network Security for Data Communication Class

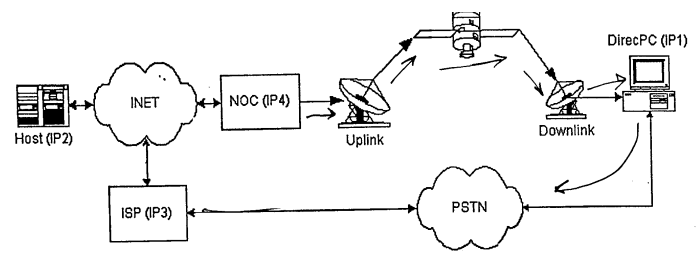

DirecPC - Detail

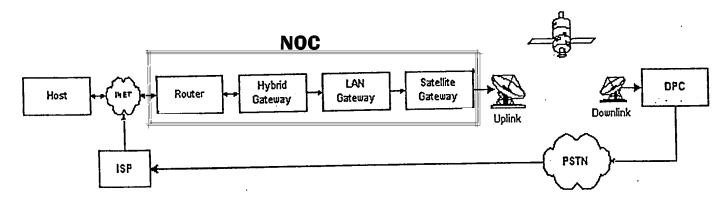

Figure 8. Project on Satellite Communication for Data Communication Class

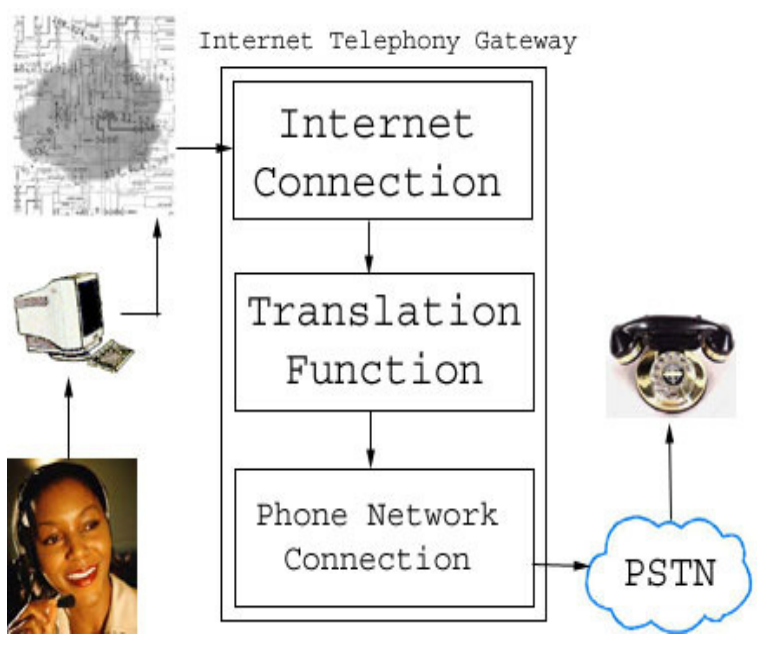

Figure 9. Project on Internet Telephony for Data Communication Class 


\section{REFERENCES}

1. American Association for the Advancement of Science [AAAS], Project 2061. (1993). Benchmarks for science literacy. New York: Oxford University Press.

2. Fujii, N., Imai, A., Abe, T., Suzuta, N., Yukita, S., Kunii, T. L., \& Koike, N. (2003). Top-down education for digital logic design course based on cellular methods. ASEE/IEEE Frontiers in Education conference. Boulder CO USA, T2F8T2F14.

3. Greca, A. N., Cook, R. P., \& Harris, J. K. (2004). Enhancing learning in a data communication and networking course with laboratory experiments. The Journal of Computing Sciences in Colleges, 19(3), 7988.

4. Greca, A. N., Harris, J. K., \& Butler, S. E. (2005). WIP-Integrating students' research project into the digital logic course to enhance learning. ASEE/IEEE Frontiers in Education International Conference. Indiana IN USA.

5. Hennessy, J. L., \& Patterson, D. A. (1998). Computer Organization and design. Morgan Kaufmann Publisher, $3^{\text {rd }}$ Ed.
6. Mano, M. M., \& Kime, C. (2004). Logic and computer design fundamentals. Prentice Hall, $3^{\text {rd }}$ Ed.

7. McCombs, B. L. The learner-centered framework on teaching and learning as a foundation for electronically networked communities and cultures. Available: http://www.pt3.org/VQ/html/mccombs.html

8. Novak, J., (1998). Learning, Creating, and using knowledge. Erlbaum, Lawrence Associates, Inc.

9. Roth, C. H. Jr., (1998). Digital system design using VHDL. PWS Publishing Comp. $3^{\text {rd }} \mathrm{Ed}$.

10. Schlag, P. V., (2004). Global knowledge surrounds learning technology offers learnercentered training. Available: http://www.ltimagazine.com/ltimagazine/article

11. Soloway, E., Jackson, S. L., Klein, J., Quintana, C., Reed, J., Spitulnik, J., Straford, S., Jul, S., Eng, J., \& Scala, N. (2003). Learning theory in practice: case studies of learner-centered design. Available: http://www.acm.org/sigchi/chi96/proceedings/pa persSoloway/es_txt.html

12. Tanenbaum, A. S. (2003). Computer Networks. Prentice

Hall, 4th

Ed. 